Review Article

\section{Rubella infection: Advances and challenges in the diagnosis and prevention of Congenital Rubella Syndrome}

\author{
Amélia Nkutxi Vueba1* and Maria do Céu Sousa ${ }^{1,2}$ \\ ${ }^{1}$ Faculty of Pharmacy, University of Coimbra (FFUC), Coimbra, Portugal \\ ${ }^{2}$ Center for Neuroscience and Cell Biology (CNC), University of Coimbra, Portugal
}

\section{Abstract}

Rubella remains an important pathogen worldwide, with many cases of congenital rubella syndrome per year. Rubella vaccination is included in the vaccination program of many countries. WHO has set goals for the elimination of measles and rubella and prevention of congenital rubella syndrome by 2020 . Worldwide, the rubella vaccine is highly effective and safe, and as a result, endemic rubella transmission has been halted in the Americas since 2009. Incomplete rubella vaccination programs result in continuous disease transmission, as evidenced by major recent outbreaks in some countries around the world. In this review, we present the rubella control, elimination and eradication policies and a brief review of the rubella laboratory diagnosis.

\section{More Information}

*Address for Correspondence: Amélia Nkutxi Vueba, Faculdade de Farmácia da Universidade de Coimbra, 3000-548 Coimbra, Portugal, Tel: +351239-826541; Email: anvueba@student.uc.pt

Submitted: 23 January 2020

Approved: 03 February 2020

Published: 04 February 2020

How to cite this article: Vueba AN, do Céu Sousa M. Rubella infection: Advances and challenges in the diagnosis and prevention of Congenital Rubella Syndrome. Int J Clin Virol. 2020; 4: 006-013.

DOI: dx.doi.org/10.29328/journal.ijcv.1001007

Copyright: @ 2020 Vueba AN, et al. This is an open access article distributed under the Creative Commons Attribution License, which permits unrestricted use, distribution, and reproduction in any medium, provided the original work is properly cited.

Check for updates

OPEN ACCESS

\section{Introduction}

Rubella is caused by a virus in the Togaviridae family, genus Rubivirus. It is a benign disease characterized by a macular rash accompanied by low fever, joint pain, pharyngitis and cervical adenopathies. The infection can in some cases be asymptomatic, although it can become severe when it occurs during pregnancy [1]. The teratogenic properties of the rubella virus were first discovered in Australia in 1941 by Gregg who associated the occurrence of rubella during pregnancy with the presence of congenital cataracts [2].

The most common form of transmission is through direct contact with droplets with the respiratory secretions of infected people. In addition, transmission can also be congenital $[3,4]$.

The severity of fetal infection is related to the time of pregnancy in which maternal infection occurs, being more severe in the period of organogenesis ( $1^{\text {st }}$ trimester of pregnancy), due to the high tropism of the virus to fetal tissues [3].

Rubella infection in pregnant women can cause devastating results, such as spontaneous abortion, fetal death and birth defects [5]. If the primary infection is contracted in the first three months, the likelihood of the appearance of "Congenital Rubella Syndrome (CRS)" is high [4,6]. A newborn
(NB) with CRS may present major malformations (cataracts, congenital glaucoma, heart disease, deafness, microcephaly, retinopathy), minor type (purple, thrombocytopenia, jaundice splenomegaly in the first 24 hours of life) or present with jaundice asymptomatic condition at birth, in which later clinical manifestations such as partial deafness or psychomotor delay may appear [4].

CRS remains a public health problem in a significant number of countries. Therefore, global health experts encourage the use of rubella vaccination, with the main objective of preventing CRS $[5,7]$.

Rubella is a vaccine-preventable infection and is considered potentially eradicable. As a result of the vaccination program in many high-income countries and in some low- and middleincome countries, the estimated number of CRS cases has declined globally from around 119000 cases in 1996 to around 105000 cases in 2010 [8,9]. The scale vaccination program in the Americas and Europe has managed to dramatically reduce or eliminate both the virus and CRS. In contrast, the highest risk of CRS is found in countries where the rubella-containing vaccine (VCR) has not been introduced in the national immunization program or vaccination coverage is low [8].

There is a growing recognition of the importance of going beyond national analyzes and considering heterogeneity 
within countries to assess public health interventions with VCR [5,10]. High acceptance can disrupt endemic rubella transmission and prevent CRS cases, as demonstrated by the World Health Organization (WHO) [5,11]. In contrast, countries in the WHO regions of Southeast Asia and Africa, which have been the slowest to add VCR to their national vaccination programs, have the highest incidence of CRS, suffering $84 \%$ of the estimated 105.000 global incidence cases of CRS in $2010[5,9]$.

\section{Epidemiology}

Rubella occurs worldwide, with a seasonal distribution. The incidence of infection tends to peak in winter or early spring countries and during spring in countries with temperate climates [12]. The prevalence estimated through the seropositivity of the population varies between countries according to their geographic characteristics and the outbreaks still occur among unvaccinated individuals [12]. In 1969, prior to the introduction of the rubella vaccine, widespread outbreaks generally occurred every 6-9 years in the USA and 3-5 years in Europe, mainly affecting children aged 5-9 years. Since the introduction of the vaccine, occurrences have become rare in countries with high rates of infection $[5,10]$.

A rubella pandemic started in Europe between 1962 and 1963 and in the USA between 1964 and 1965. Among the Americans, there were about 12.5 million cases with 11.000 fetal deaths; about 20.000 newborns were born with malformations compatible with CRS; 11.000 with deafness; 3.500 with blindness; 1.800 with mental retardation and 2.100 died in the neonatal period [5]. The costs of controlling this epidemic were very high (estimated at approximately two billion dollars), making it one of the biggest epidemics of the disease on record. As a consequence of the epidemic, in 1966, rubella and CRS became notification diseases in the USA. In this way, it was possible to establish the registration of cases and the dynamic monitoring of rubella and CRS due to the strategies adopted. These records point to 1969 as the year with the highest number of cases: 57.686. The incidence of rubella until 1968 was 24.4 cases / 100.000 inhabitants, with children aged from 5 to 9 years being the most affected, with 101.3 cases / 100.000 inhabitants [13].

Between 1969 and 1988 there was a 99\% reduction in the incidence of rubella. This great decrease was a direct result of the strategies adopted for rubella control, which was accompanied by a reduction in the incidence of CRS. During the 1964 epidemic, this incidence was 16 cases / 100.000 live births, falling to 2.7 cases / 100.000 live births in 1969 [14,15]. In the 1980s and early 1990s, rubella vaccination strategies in the Americas evolved rapidly. The leadership was taken by the English-speaking Caribbean countries, which included rubella vaccine in their efforts to eliminate measles. The Caribbean strategy was effective and included two main components: a) Mass vaccination in both sexes, aged up to 40 years, with the double viral or triple viral vaccine, to provide protection and decrease the risk of pregnant women becoming infected with the rubella virus;

b) The introduction of the rubella vaccine in the regular immunization schedule of children and young people [11].

The successful implementation of the highly effective VCR (chickenpox, mumps and rubella) can best be exemplified by the experience in Finland, where the 2-dose scheme introduced since 1982 reduced all CRS diseases to 0.1 per 100.000 inhabitants in 1995 [16]. A more recent example is Spain, where a $54 \%$ increase in VCR vaccine coverage from 2003 (one dose) to 2013 (two doses) resulted in 95.5\% of mothers and $96.4 \%$ of their newborns having protective levels of anti-rubella IgG [17]. Even so, ironically, there are emerging reports of decreased rubella immunity and decreased incidence of protective antibody levels ( $\geq 10 \mathrm{IU} / \mathrm{ml}$ ) among women born after the introduction of routine universal rubella immunization in European and Asian countries $[16,18,19]$. In fact, national investigators in Ireland showed that rubella seronegativity was $14.7 \%$ among pregnant women aged $<25$ years compared to $5.0 \%$ of older pregnant women $[16,18]$. The above observations have led to the concern that the CRS vaccination program can only be effective in preventing childhood rubella $[16,19]$.

In the USA, after the vaccine was licensed in 1969, the incidence decreased by $99 \%$ until reaching 20 years of age and in Chile approximately by $100 \%$ [20-22].

In some African countries, rubella seropositivity in women of reproductive age is between $71 \%-99 \%$. Countries with higher incidence included Mozambique (95\%) and South Africa (97\% - 98\%) [12]. In 2011, a measles surveillance campaign implemented in the Kinshasa, capital of Democratic Republic of Congo (DRC), showed that $24 \%$ of blood samples screened were positive for rubella IgM antibodies [12,23]. Although knowledge of the geographic distribution of rubella virus genotypes has grown substantially since 2003, the genotypes present in many countries and regions remain unknown $[12,24]$.

In 2011, WHO updated the guidelines on the preferred strategy for the introduction of VCR in national vaccination programs and recommended an initial vaccination campaign, aimed at children aged 9 months to 14 years. The Global Vaccine Action Plan 2011-2020 (GVAP), approved by the World Health Assembly in 2012, includes goals to eliminate rubella in at least five of the six WHO regions by $2020[12,25]$.

Global coverage with VCR increased from 21\% in 2000 to $40 \%$ in 2012 and to $47 \%$ in 2016. In 2000, just over half $(99$. $51 \%$ ) of countries had introduced VCR into their vaccination schedule; by the end of 2012, more than two thirds (132. 
$68 \%$ ) of countries were using VCR. By 2014, at the time of the last world update, eight of the other countries introduced VCR, bringing the total number of countries using VCR to $140(72 \%)[12,25]$. VCR was introduced into the routine vaccination schedule in 152 (78\%) countries, including $13(28 \%)$ in the African Region, 16 (76\%) in the Eastern Mediterranean Region, 8 (73\%) in Southeast Asia and all 115 countries in the Region of the Americas, Europe Region and Western Pacific Region [12,25]. In December 2016, 152 (78\%) of the 194 countries introduced VCR into the national immunization calendar, representing an increase from 53 countries since 2000, including 20 countries that introduced VCR after 2012 [25].

The rubella and CRS elimination targets were set by the European Region (target date: 2015) and Western Pacific Region (target date to be determined), while the Southeast Asia Region has a rubella and CRS control target [12,25]. Neither the African Region nor the Eastern Mediterranean Region has set regional goals or targets for rubella. Since rubella cases are detected through measles surveillance and because the rubella vaccine is generally administered as a combined measles and rubella vaccine, the elimination activities for both diseases are programmatically linked, and the elimination activities for measles can be used to support rubella elimination [25].

Rubella and CRS surveillance is necessary to assess disease burden prior to the introduction of VCR, and to monitor disease burden and epidemiology after their introduction. Also, the surveillance is important to identify pregnant women infected with rubella virus that need follow-up to assess pregnancy outcomes and identifying, diagnosing and managing CRS in affected babies. Countries report information on immunization schedules, vaccination campaigns, and number of vaccine doses administered through routine immunization services and other WHO monitoring data in conjunction with the United Nations International Children's Emergency Fund (UNICEF) each year using the Joint Report Form (JRF) Joint Report Form " [12]. Surveillance data, including the number of rubella and CRS cases, are also reported to WHO and UNICEF through the JRF using standard case definitions $[12,25]$.

Routine administration of VCR is recommended as a combined vaccine or simultaneously, at the same visit; this recommendation was implemented in 144 (95\%) of the 152 countries that introduced the vaccine. Based on the vaccination programs of each country, the first dose of measles, mumps and rubella vaccine is scheduled for 8-11 months in 27 (18\%) countries, and at $12-18$ months in $125(83 \%)$ ) countries. VCR is supplied as a vaccine combined with a measles vaccine in 30 countries $(20 \%)$ and combined with a measles and mumps vaccine (with or without chickenpox vaccine) in 122 countries $(80 \%)[12,25]$. The WHO recommends that all countries that have not yet introduced rubella vaccine should consider doing so using existing and well-established measles immunization programs. To date, three WHO regions have set goals to eliminate this preventable cause of birth defects. In 2015, the WHO Region of the Americas became the first in the world to be declared free of endemic rubella transmission $[12,25]$. The number of countries that use rubella vaccines in their national program continues to increase steadily. As of December 2016, 152 of the 194 countries had introduced rubella vaccines; however, national coverage ranges from 13\% to $99 \%$. Reported rubella cases decreased by $97 \%$, from 670.894 cases in 102 countries in 2000 to 22.361 cases in 165 countries in 2016. CRS rates are highest in WHO regions of Africa and Southeast Asia where vaccination coverage is lowest $[12,25]$.

In Angola, there are no known rubella seroprevalence studies in the population. In fact, in April 2012, the Measles Initiative - now known as the Measles and Rubella Initiative - launched a Global Strategic Plan for Measles and Rubella, covering the period 2012-2020. The Plan includes global targets for 2015 and 2020 [12,25].

\section{Transmission}

Rubella is transmitted mainly by direct contact with individuals infected by droplets of nasopharyngeal secretions. The upper respiratory tract and nasopharyngeal lymphoid tissue appear to be the first sites of virus replication, and the virus then spreads to regional lymph nodes. Indirect transmission, through contact with objects contaminated with nasopharyngeal secretions, blood and urine is uncommon [1]. Rubella is also transmitted via the transplacental route from the mother to the fetus. The child with congenital rubella can eliminate the virus through urine and nasopharyngeal secretions $[3,26]$. Rubella's incubation period varies from 12 to 23 days, lasting an average of 17 days. After exposure to the virus, usually occurs maculopapular rashes, first on the face and spreading to the rest of the body $[1,27]$. The greatest transmissibility is observed in the period between seven days before the appearance of the characteristic rash of the disease until the seventh day after its disappearance. Children with congenital rubella can eliminate the virus for more than 1 year, and transmission is greatest in the first months of life. Passive immunity is acquired by maternal antibodies and active immunity by natural infection or vaccination. Children of immune mothers generally remain protected by maternal antibodies for the first 6 to 9 months of life. Active immunity is long-lasting and is believed to remain lifelong [27].

Transmission of the virus to the fetus occurs after transplacental passage of the virus during maternal viremia. This transmission is directly influenced by gestational age at the time of primary maternal infection. The rate of maternalfetal transmission is $90 \%$ in the first 12 weeks of gestation, with a decline between 12 to 28 weeks of gestational age and increasing again at the end of the 3rd trimester of pregnancy, when it can reach up to $100 \%$. In cases of maternal infection ( $1 \%$ to $3 \%$ of individuals), replication of the virus in the 
pharynx persists for a short period and without demonstrable viremia, thus being the insignificant risk to the fetus [27]. The infected NB will become a reservoir of the virus, spreading the disease later: viral elimination can occur up to 18 or 24 months of age ( $80 \%$ transmissibility in the first month of life; $62 \%$ from the first to the fourth month; 33\% between the fifth and eighth month; $11 \%$ between nine and twelve months and $3 \%$ in the second year of life) [27].

\section{Clinical manifestations}

Rubella is characterized by a diffuse maculopapular and punctiform rash, which begins on the face, scalp and neck, and subsequently spreads to the entire body. Low fever and the presence of retroauricular, cervical and occipital lymphadenopathy, which usually precede the rash (5 to 10 days) are signs that contribute to the differential diagnosis in relation to other rash diseases $[1,28]$. In general, a prodromal period is not observed in children with rubella. Adolescents and adults may present prodromes with low fever, headache, generalized pain (arthralgia and myalgia), conjunctivitis, runny nose and cough. About $25 \%$ to $50 \%$ of rubella virus infections are subclinical. Viremia occurs for about 7 days before the rash appears which disappears when the humoral immune response begins to develop [28,29].

Rubella can cause complications, with transient joint involvement, such as arthritis and arthralgia, being the most frequent. Interestingly, these symptoms are more prevalent and severe in women infected with rubella virus than in men [29].

More serious complications, including thrombocytopenic purpura and post-infectious encephalopathy orencephalomyelitis, are occasionally associated with rubella acquired in the postnatal period. A rare and generally fatal neurodegenerative disease, called progressive rubella panencephalitis, has also been reported as a late complication of rubella in childhood [30].

The main concern represented by rubella is its teratogenicity, with maternal infection in early pregnancy leading to CRS in children [30]. There is more than an $80 \%$ risk of birth defects when viral infection is acquired in the first 12 weeks of pregnancy (1st trimester) [31]. The time when the infection occurs during pregnancy can influence the outcome. The earlier in pregnancy the maternal infection occurs, the more severe the damage to the fetus. The risk of fetal infection and the severity of congenital abnormalities decreases after the first trimester; after 17 weeks of gestation, the risk of developing any defects is low [31]. The effects of rubella infection in pregnancy are unpredictable, ranging from normal birth, spontaneous abortion, death shortly after birth or even birth with simple or combined abnormalities, such as damage to the central nervous system, leading to delayed physical growth and mental, microcephaly, encephalitis, hepatomegaly, cardiac malformations, pneumonia, eye and hearing defects [26]. Insulin-dependent diabetes mellitus commonly occurs as a late sequel to CRS, and defects such as deafness may not be detected initially. CRS cases have been reported after maternal reinfection, although this appears to be a rare phenomenon [32]. As with primary rubella infection, gestational age at the time of reinfection influences the likelihood of fetal abnormalities. No case of rubella reinfection that causes CRS has been reported after 12 weeks [33].

\section{Diagnosis}

Many diseases have a clinical presentation similar to rubella and up to $50 \%$ of rubella infections can be sub-clinical [34]. The diagnosis of rubella in general is usually done through the clinical picture. That is later confirmed by laboratory tests, such as the search for anti-rubella antibodies. Laboratory tests, serology and / or viral isolation and Polymerase Chain Reaction (PCR), are essential for establishing the diagnosis [21,33]. Rubella virus can be isolated from nasal fluid, blood, throat, urine and cerebrospinal fluid samples from patients with rubella and CRS. The virus can be isolated from the pharynx 1 week before and up to 2 weeks after the rash starts. Although virus isolation is a diagnosis of rubella infection, viral cultures are laborious and therefore are not done in many laboratories; they are generally not used for the routine diagnosis of rubella. However, viral isolation is an extremely valuable epidemiological tool and should be used in all suspected cases of rubella or CRS [21].

Serology is the most common method of diagnosing rubella. Acute rubella infection can be confirmed by a significant increase in the antibody titre against rubella in serum samples or by the presence of serum anti-rubella IgM. The serum should be collected as soon as possible (within 7 to 10 days) after the onset of the disease and again 14 to 21 days (minimum of 7) days' later [35].

However, false positives can occur in IgM detection, depending mainly on the methodology used for the detection of immunoglobulins in serum [35]. False positive IgM tests for rubella occurred in people with parvovirus infections, with a positive heterophile test for infectious mononucleosis or with positive rheumatoid factor. The serological tests available for laboratory confirmation of rubella infections vary between laboratories [34].

The Enzyme-Linked Immunosorbent Assay (ELISA) is sensitive, widely available and relatively easy to perform, and can also be modified to measure IgM antibodies. [34]. During prenatal care, it is recommended to request maternal serology for rubella in the first consultation, with the aim of knowing the immune status of the pregnant woman [35].

\section{Differential diagnosis}

The differential diagnosis must be made for other febrile exanthematic diseases such as measles, scarlet fever, dengue, sudden rash (children up to 2 years old), infectious erythema, 
enteroviruses (coxsackie and echo) and also for other diseases that can cause congenital syndromes, such as infectious mononucleosis, toxoplasmosis and cytomegalovirus infection [1].

\section{Diagnosis of maternal and fetal infection}

In pregnant women, laboratory diagnosis is made by isolating the virus or by serological methods for detecting specific antibodies, and it is necessary to ensure the collection of the blood sample at the first visit. The most used test is the ELISA for the detection of specific IgM and IgG antibodies and / or for the identification of the virus from the secretion of the nasopharynx and urine, until the fifth day, preferably, on the third day of the onset of the rash [1,34.].

In case of contact of the pregnant woman with a suspected rubella patient, blood collection should be done within a short period of time after contact. Samples collected after 28 days, although considered late, should also be sent to the laboratory for IgM research [2]. The rubella virus-specific IgM antibodies appear soon after the onset of the disease. The presence of positive IgM means that there has been a recent infection, but they are generally not detected after 4 to 6 weeks of the rash onset. IgG antibodies usually persist for life. It is important to remember that non-reactive results for IgM do not rule out the possible recent rubella virus infection $[2,3]$.

The prenatal diagnosis aims to clarify with greater accuracy whether or not there was fetal involvement. Thus, the decision for an abortion can be guided more appropriately, based on scientific data and not just on probability. According to the Rubella Control Plan Standard [2,3] the diagnosis of pregnant women in prenatal care is indicated when:

- Seroconversion is confirmed during the prenatal period, up to the 16th week;

- There is confirmation of the late maternal diagnosis of rubella or contact with the infected patient;

- There is doubt in the maternal diagnosis, but in a period of significant risk for the fetus;

- Reinfection is suspected or confirmed.

The diagnosis of fetal infection can be made through cordocentesis performed after the $22^{\text {nd }}$ week of pregnancy. Before that the immaturity of the fetal immune system combined with the immunological depression caused by the virus can generate false-negative results. The intrauterine diagnosis is based on the finding of changes in fetal blood: positive IgM for rubella; isolation of the virus; or identification of viral RNA. Some nonspecific signs of the infection may also be present in fetal blood: anemia, thrombocytopenia, elevated Gamma Glutamyl Transferase, Lactic Dehydrogenase and Interferon.
Due to the fact that the vaccine consists of live viruses, there is concern about the theoretical possibility of CRS after inadvertent administration during pregnancy $[2,3]$. Thus, it is recommended that women who received the vaccine avoid conception for a period of up to one month after the vaccine dose. Although several studies have demonstrated the safety of the vaccine, this procedure would avoid doubts in the diagnosis of any problem that could occur with the NB [3]. Women who are pregnant or become pregnant soon (up to 30 days) inadvertently get the vaccine must be carefully monitored by a doctor [2]. As for postnatal diagnosis, the fetus is capable of producing specific antibodies, IgM and IgG for rubella, even before birth. The presence of specific IgM in the newborn's blood shows congenital infection, since this immunoglobulin does not cross the placental barrier [2].

In $100 \%$ of children with CRS, IgM antibodies can be detected up to the $5^{\text {th }}$ month and in about $60 \%$, between 6 and 12 months, and are rarely detected after the $18^{\text {th }}$ month [2]. Laboratory diagnosis of suspected CRS cases is made by taking a blood sample for investigation shortly after birth, in cases where maternal infection is suspected or confirmed during pregnancy, or at the time of suspected diagnosis in children less than one year of age [3]. Serology detects IgM levels in the NB or by monitoring IgG levels for a prolonged period of up to 2 years. Stable or elevated levels of IgG confirm the diagnosis while their drop suggests the presence of maternal IgG [2].

\section{Real-Time PCR (RT -PCR)}

Real-time PCR (RT-PCR) technology is an evolution of the PCR method. Its principle is based on the duplication of DNA strands "in vitro" that can be repeated several times, generating enough DNA to perform several analyzes. With just a single fragment of DNA it is possible to reproduce millions of copies [36].

RT-PCR tests are much more sensitive, specific and quick, especially when compared to conventional tests, taking 2 to 3 hours to output the result. They are widely used in the diagnosis of infectious diseases, in which the culture of the causative agents can be very difficult or even impossible [37]. The progress in the diagnostic techniques of rubella, has allowed, in addition to serology, the detection of viral RNA in clinical samples by the PCR method, enabling rapid and highly sensitive detection. RT-PCR is currently the most widely used laboratory technique to confirm acute rubella infection [38]. Suitable samples include throat/nose secretions, nasopharyngeal aspirates, urine or peripheral blood mononuclear cells $[39,40]$. The diagnosis of congenital rubella infection is mainly based on the detection of rubella virus in amniotic fluid by RT-PCR [41,42] (or detection of rubella virus-specific IgM antibody in fetal blood $[43,44]$. The fast and accurate identification of the rubella virus is very important in pregnant women as it helps to guide prenatal treatment and identify the need for long-term follow-up. In 
addition, in many countries, maternally rubella clinically confirmed in the first 8 weeks of pregnancy is considered an indication for therapeutic abortion due to the high incidence of birth defects $[45,46]$.

The RT-PCR require little manipulation, thus reducing the risk of contamination, and generally reach small fragments, thus allowing detection even in case of partial RNA degradation $[39,47]$.

The high sensitivity of this technique allows excellent results, but it is also subject to the presence of inhibitors and contamination that can affect its efficiency [46].

\section{Treatment}

Currently, there is no specific treatment for rubella. The signs and symptoms presented must be treated according to the symptomatology and appropriate therapy [16]. The most important thing, however, will be to promote control and minimize possible sequelae in case of teratogenic effects, with interdisciplinary monitoring [16].

\section{Prevention and control}

Rubella is a vaccine-preventable infection and considered potentially eradicable [5]. CRS remains a public health problem in a significant number of countries. Therefore, global health experts encourage the use of rubella vaccination, with the main objective of preventing CRS [5,7]. Promoting health education in the population, clarifying the population about the importance of vaccinating children and women, is the main control measure to decrease the circulation of the rubella virus, in order to prevent CRS [16].

Immunity is acquired by natural infection or by vaccination, being durable after natural infection and remaining for almost a lifetime after vaccination. The vaccine is composed of attenuated viruses, grown in rabbit kidney cells or in human diploid cells. It can be produced in monovalent form, associated with measles (viral double) or with measles and mumps (triple viral). The vaccine is presented in lyophilized form, and must be reconstituted for use. After its reconstitution, it must be kept at a positive temperature of $2{ }^{\circ} \mathrm{C}$ to $8{ }^{\circ} \mathrm{C}$, at the local and regional levels. At the central level, the recommended temperature is minus $20^{\circ} \mathrm{C}$. It must be kept protected from light, so as not to lose activity [16]. The vaccine is used in a single dose of $0.5 \mathrm{~mL}$ subcutaneously. Children of immune mothers generally remain protected by maternal antibodies around six to nine months after birth $[8,16]$. The triple viral vaccine is recommended for all children (two doses), adolescents and adults (men and women), especially women who have not had contact with the disease. Pregnant women should not be vaccinated and vaccinated women should avoid pregnancy until the month following vaccination due to the risk of contamination of the fetus (even if the virus is weakened it can cross the placenta) [34]. All infected people should avoid public places (such as schools, work and busy streets) during the disease period [34]. The vaccine is highly effective and is unlikely to generate side effects. Non-immunized adults and adolescents can also get the vaccine [34]. The scale vaccination program in the Americas and Europe has managed to dramatically reduce or eliminate both the virus and CRS. In contrast, the greatest risk of CRS is found in countries where VCR has not been introduced in the national immunization program or the vaccination coverage is low [8].

Despite the high prevalence of rubella in Africa, the infection had never been studied in Angola. Thus, a study was carried out by us between May 2016 and August 2017, regarding the assessment of rubella seroprevalence in 396 pregnant women in the province of Luanda. The results showed that there are a high number of women (87.6\%) with previous exposure to rubella [48]. In Angola, the rubella vaccine was included, as of the year 2017, in the National Vaccination Calendar, a decision by the Ministry of Health (MINSA) that aims to prevent the increasing birth of children with malformation or with congenital rubella. This decision by MINSA is based on the strategy for the combined immunization of the vaccine against rubella and measles, because the symptoms of rubella are confused with those of measles and with the naked eye it is not possible to make the distinction correctly, being only possible with laboratory tests, to be distinguished accurately. However, despite the lack of official data on cases of congenital rubella, it is estimated that the situation is not yet "as alarming" according to MINSA of Angola [49]. It is important to emphasize that the introduction of vaccines in any country depends a lot on the epidemiological situation, on the existence of qualified human resources, on sustainable financing and on cold chain conditions to ensure the conservation and quality of the vaccine to be introduced $[49,50]$.

\section{Conclusion}

Despite the progress made on rubella elimination and the significant gains made, rubella elimination is not close to achieving the ambitious targets set in the WHO GVAP 20112020. The VCR vaccine is highly effective and safe. Significant health policies and public health campaigns in the Americas have shown that rubella virus transmission can be stopped and the disease eliminated. Additional efforts should be made to ensure that people have the opportunity to be fully immunized according to their countries' immunization schedule. In addition, it would be beneficial to have a nonliving viral vaccine that could be used in all patients and populations. On the other hand, further advances are needed in diagnostic tests of high sensitivity and low cost.

It is essential to encourage adherence by countries that do not yet comply with the WHO GVAP, demonstrating the need for global cooperation in creating a rubella-free world. The strategies included in the GVAP are sound, although their full implementation is often limited by the lack of global and national political will reflected in the lack of resources. 
Reorienting the rubella elimination program in these countries is essential to increase the emphasis on surveillance, so that programmatic and strategic decisions can be guided by the data.

\section{Acknowledgment}

This work was financed by the European Regional Development Fund (FEDER), through the Centro 2020 Regional Operational Programme under project CENTRO-01-0145FEDER-000008: Brain Health 2020 and through the COMPETE 2020-Operational Programme for Competitiveness and Internationalization and Portuguese national funds via FCTFundação para a Ciência e a Tecnologia, I.P., under strategic project POCI-01-0145-FEDER-007440 (UID/NEU/04539/2013); Calouste Gulbenkian Foundation, Lisbon, Portugal for the Ph.D. scholarship grant (ref. 104/SBG/17). We would also like to thank the Lucrecia Paim Maternity and Sagrada Esperança Clínic.

\section{References}

1. Lambert N, Strebel P, Orenstein W, Icenogle J, Poland GA. Rubella. Lancet. 2015; 385: 2297-2307.

PubMed: https://www.ncbi.nlm.nih.gov/pubmed/25576992

2. Bukasa $A$, Campbell $H$, Brown $K$, Bedford $H$, Ramsay $M$, et al. Rubella infection in pregnancy and congenital rubella in United Kingdom, 2003 to 2016. Euro Surveill. 2018; 23: 17-00381.

PubMed: https://www.ncbi.nlm.nih.gov/pubmed/29766840

3. Yeshwondm M,Balkachew N, DelayehuB, Mekonen G. Seroepidemiology Study of Cytomegalovirus and Rubella among Pregnant Women at St. Paul's Hospital Millennium Medical College, Addis Ababa, Ethiopia. Ethiop J Health Sci. 2016; 26: 427-438.

PubMed: https://www.ncbi.nlm.nih.gov/pubmed/28446848

4. Karacan $M$, Batukan $M$, Cebi $Z$, Berberoglugil $M$, Levent $S$, et al Screening cytomegalovirus, rubella and toxoplasma infections in pregnant women with unknown pre-pregnancy serological status. Arch Gynecol Obstet. 2014; 290: 1115-1120.

PubMed: https://www.ncbi.nlm.nih.gov/pubmed/25027818

5. Winter AK, Pramanik S, Lessler J, Ferrari M, Grenfell BT, et al. Rubella vaccination in India: identifying broad consequences of vaccine introduction and key knowledge gaps. Epidemiology and Infectious. 2018; 146: 65-77.

6. Rasti S, Ghasemi FS, Abdoli A, Piroozmand A, Mousavi SG, et al. ToRCH "co-infections" are associated with increased risk of abortion in pregnant women. Congenital Anomalies (Kyoto). 2016; 56: 73-78. PubMed: https://www.ncbi.nlm.nih.gov/pubmed/26499091

7. Martínez-Quintana E, Castillo-Solórzano C, Torner N, RodríguezGonzález F. Congenital rubella syndrome: a matter of concern. Rev Panam Salud Publica. 2015; 37: 179-186.

PubMed: https://www.ncbi.nlm.nih.gov/pubmed/25988255

8. Tamirat B, Hussen S, Shimelis T. Rubella virus infection and associated factors among pregnant women attending the antenatal care clinics of public hospitals in Hawassa City, Southern Ethiopia: a cross-sectional study. BMJ Open. 2017; 7: e016824.

PubMed: https://www.ncbi.nlm.nih.gov/pubmed/28982820

9. Vynnycky E, Yoshida LM, Huyen DT, Trung ND, Toda K, et al. Modeling the impact of rubella vaccination in Vietnam. Human Vaccines \& Immunotherapeutics. 2016; 12: 150-158.

PubMed: https://www.ncbi.nlm.nih.gov/pubmed/26260857
10. Plotkin S. History of vaccination. Proc Natl Acad Sci U S A. 2014; 111: 12283-12287.

PubMed: https://www.ncbi.nlm.nih.gov/pubmed/25136134

11. Su Q, Ma C, Wen N, Fan C, Yang H, et al. Epidemiological profile and progress toward rubella elimination in China. 10 years after nationwide introduction of rubella vaccine. Vaccine. 2018; 36: 2079-2085. PubMed: https://www.ncbi.nlm.nih.gov/pubmed/29550193

12. Zanga J, Mbanzulu MK, Kabasele AF, Ngatu NR, Wumba DR. Rubella Seroprevalence and real-time PCR detection of RUBV among Congolese pregnant women. BMC Infect Dis. 2017; 17: 250. PubMed: https://www.ncbi.nlm.nih.gov/pubmed/28381214

13. Orenstein WA, Hinman A, Nkowane B, Olivé JM, Reingold AL. Measles and Rubella Global Strategic Plan 2012-2020 midterm review. Vaccine. 2018; 36 Suppl 1: A1-A34.

PubMed: https://www.ncbi.nlm.nih.gov/pubmed/29307367

14. Grant GB, Desai S, Dumolard L, Kretsinger K, Reef SE. Progress toward Rubella and Congenital Rubella Syndrome Control and Elimination Worldwide, 2000-2018. MMWR Morbidity and Mortality Weekly Report. 2019; 68: 855-859.

15. Wu Y, Wood J, Khandaker G, Waddington C, Snelling T. Informing rubella vaccination strategies in East Java, Indonesia through transmission modelling. Vaccine. 2016; 34: 5636-5642.

PubMed: https://www.ncbi.nlm.nih.gov/pubmed/27670077

16. Hui SYA, Sahota DS, Lao TT. Impact of the two-dose rubella vaccination regimen on incidence of rubella seronegativity in gravidae aged 25 years and younger. PLoS One. 2017; 12: e0183630. PubMed: https://www.ncbi.nlm.nih.gov/pubmed/28854204

17. Plans $\mathrm{P}$, de Ory F, Campins $\mathrm{M}$, Álvarez E, Payà T, et al. Prevalence of antirubella, anti-measles and anti-mumps IgG antibodies in neonates and pregnant women in Catalonia (Spain) in 2013: susceptibility to measles increased from 2003 to 2013. Eur J Clin Microbiol Infect Dis. 2015; 34: 1161-1171.

PubMed: https://www.ncbi.nlm.nih.gov/pubmed/25666082

18. O'Connor C, Le Blanc D, Drew RJ. Epidemiological changes in rubella IgG antibody levels detected in antenatal women from a retrospective rubella seroprevalence study. Ir J Med Sci. 2018; 187: 689-692. PubMed: https://www.ncbi.nlm.nih.gov/pubmed/29209940

19. Skidmore S, Boxall E, Lord S. Is the MMR vaccination programme failing to protect women against rubella infection? Epidemiology and Infection. 2014; 142: 1114-1117.

PubMed: https://www.ncbi.nlm.nih.gov/pubmed/23953764

20. Andrus JK, Cochi SL, Cooper LZ, Klein JD. Combining Global Elimination of Measles and Rubella with Strengthening Of Health Systems in Developing Countries. Health Affairs (Millwood). 2016; 35: 327-33. PubMed: https://www.ncbi.nlm.nih.gov/pubmed/26858388

21. Bouthry E, Picone O, Hamdi G, Grangeot-Keros L, Ayoubi JM, et al. Rubella and pregnancy: diagnosis, management and outcomes. Prenatal Diagnosis. 2014; 34: 1246-53.

PubMed: https://www.ncbi.nlm.nih.gov/pubmed/25066688

22. Seppälä EM, López-Perea N, Torres de Mier MV, Echevarría JE, Fernández-García $\mathrm{A}$, et al. Last cases of rubella and congenital rubella syndrome in Spain, 1997-2016: The success of a vaccination program. Vaccine. 2019; 37: 169-175.

PubMed: https://www.ncbi.nlm.nih.gov/pubmed/30454948

23. Pukuta E, Waku-Kouomou D, Abernathy E, Illunga BK, Obama R, et al. Genotypes of rubella virus and the epidemiology of rubella infections in the Democratic Republic of the Congo, 2004-2013. J Med Virol. 2016; 88: $1677-1684$.

PubMed: https://www.ncbi.nlm.nih.gov/pubmed/27479298 
24. Cheng WY, Wang HC, Liu MT, Wu HS. Molecular surveillance of rubella viruses in Taiwan from 2005 to 2011. Journal of Medical Virology. 2013; 85: 745-753.

PubMed: https://www.ncbi.nlm.nih.gov/pubmed/23417619

25. World Health Organization (WHO). Measles and Rubella Surveillance Data 10 January 2020 17:54 CET.

26. Yamamoto AY, Castellucci RA, Aragon DC, Mussi-Pinhata MM. Early high CMV seroprevalence in pregnant women from a population with a high rate of congenital infection. Epidemiol Infect. 2013; 141: 21872191.

PubMed: https://www.ncbi.nlm.nih.gov/pubmed/23200458

27. Thompson KM, Badizadegan ND. Modeling the Transmission of Measles and Rubella to Support Global Management Policy Analyses and Eradication Investment Cases. Risk Analysis. 2017; 37: 1109-1131. PubMed: https://www.ncbi.nlm.nih.gov/pubmed/28561947

28. Getahun M, Beyene B, Gallagher K, Ademe A, Teshome B, et al Epidemiology of rubella virus cases in the pre-vaccination era of Ethiopia, 2009-2015. BMC Public Health. 2016; 16: 1168.

PubMed: https://www.ncbi.nlm.nih.gov/pubmed/27863513

29. Grangeot-Keros L, Bouthry E, Vauloup-Fellous C. Rubella: a current issue? Presse Medicale. 2014; 43: 698-705.

PubMed: https://www.ncbi.nlm.nih.gov/pubmed/24785141

30. George S, Viswanathan R, Sapkal GN. Molecular aspects of the teratogenesis of rubella virus. Biol Res. 2019; 52: 47.

PubMed: https://www.ncbi.nlm.nih.gov/pubmed/31455418

31. Boucoiran I, Castillo E. No. 368-Rubella in Pregnancy. J Obstet Gynaecol Can. 2018; 40: 1646-1656.

PubMed: https://www.ncbi.nlm.nih.gov/pubmed/30527073

32. Grant GB, Reef SE, Dabbagh A, Gacic-Dobo M, Strebel PM. Global Progress Toward Rubella and Congenital Rubella Syndrome Control and Elimination - 2000-2014. MMWR Morbidity and Mortality Weekly Report. 2015; 64: 1052-1055.

PubMed: https://www.ncbi.nlm.nih.gov/pubmed/26401958

33. Kaushik A, Verma $S$, Kumar P. Congenital rubella syndrome: A brief review of public health perspectives. Indian J Public Health. 2018; 62: 52-54.

PubMed: https://www.ncbi.nlm.nih.gov/pubmed/29512566

34. Epidemiology and prevention of Vaccine- Preventable Diseases. Rubella 2019. Ref: https://www.cdc.gov/vaccines/pubs/pinkbook/ rubella.html\#congenital

35. Hübschen JM, Bork SM, Brown KE, Mankertz A, Santibanez S, et al. Challenges of measles and rubella laboratory diagnostic in the era of elimination. Clin Microbiol Infect. 2017; 23: 511-515.

PubMed: https://www.ncbi.nlm.nih.gov/pubmed/28412379

36. Namuwulya $P$, Abernathy $E$, Bukenya $H$, Bwogi J, Tushabe $P$, et al Phylogenetic analysis of rubella viruses identified in Uganda, 20032012. J Med Virol. 2014; 86: 2107-2113.

PubMed: https://www.ncbi.nlm.nih.gov/pubmed/24700073

37. Zheng Q, Abernathy ES, Sun H, Zhu Z, de Filippis A, et al. Genotyping of rubella virus RNA in sera and dried blood spots collected during routine surveillance and in archival sera. J Virol Methods. 2013; 187: 284-287. PubMed: https://www.ncbi.nlm.nih.gov/pubmed/23201287
38. Rota PA1, Brown KE, Hübschen JM, Muller CP, Icenogle J, et al Improving global virologic surveillance for measles and rubella. $J$ Infect Dis. 2011; 204: S506-S513.

PubMed: https://www.ncbi.nlm.nih.gov/pubmed/21666207

39. Hubschen JM, Kremer JR, De Landtsheer S, Muller CP. A multiplex TaqMan PCR assay for the detection of measles and rubella virus. $J$ Virol Methods. 2008; 149: 246-250.

PubMed: https://www.ncbi.nlm.nih.gov/pubmed/18353451

40. Takao S, Shigemoto N, Shimazu Y, Tanizawa Y, Fukuda S, et al. Detection of exanthematic viruses using a TaqMan real-time PCR assay panel in patients with clinically diagnosed or suspected measles. Jpn J Infect Dis. 2012; 65: 444-448.

PubMed: https://www.ncbi.nlm.nih.gov/pubmed/22996223

41. Macé $M$, Cointe $D$, Six $C$, Levy-Bruhl $D$, Parent du Châtelet $I$, et al Diagnostic value of reverse transcription-PCR of amniotic fluid for prenatal diagnosis of congenital rubella infection in pregnant women with confirmed primary rubella infection. J Clin Microbiol. 2004; 42: 4818-4820.

PubMed: https://www.ncbi.nlm.nih.gov/pubmed/15472350

42. Bosma TJ, Corbett KM, Eckstein MB, O'shea S, Vijayalakshmi P, et al. Use of PCR for prenatal and postnatal diagnosis of congenital rubella. J Clin Microbiol. 1995; 33: 2881-2887.

PubMed: https://www.ncbi.nlm.nih.gov/pubmed/8576339

43. Daffos F, Forestier F, Grangeot-Keros L, Capella Pavlovsky M, Lebon P, Chartier M, Pillot J. Prenatal diagnosis of congenital rubella. Lancet. 1984; 2: 1-3.

PubMed: https://www.ncbi.nlm.nih.gov/pubmed/6145931

44. Morgan-Capner $P$, Rodeck $\mathrm{CH}$, Nicolaides $\mathrm{KH}$, Cradock-Watson JE. Prenatal detection of rubella-specific IgM in fetal sera. Prenatal Diagnosis. 1985; 5: 21-26.

PubMed: https://www.ncbi.nlm.nih.gov/pubmed/3975220

45. Curti SP, Figueiredo CA, de Oliveira MI, Andrade JQ, Zugaib M, et al. Prenatal diagnosis of congenital rubella infection in São Paulo. Revista da Associação Medica Brasileira. 2014; 60: 451-456.

46. Hübschen JM, Bork SM, Brown KE, Mankertz A, Santibanez S, et al. Challenges of measles and rubella laboratory diagnostic in the era of elimination. Clinical Microbiology and Infection. 2017; 23: 511-515. PubMed: https://www.ncbi.nlm.nih.gov/pubmed/28412379

47. Mosquera Mdel M, de Ory F, Moreno M, Echevarria, JE. Simultaneous detection of measles virus, rubella virus, and parvovirus B19 by using multiplex. J Clin Microbiol. 2002; 40: 111-116.

PubMed: https://www.ncbi.nlm.nih.gov/pubmed/11773102

48. Vueba NA, Sousa MC. Seroprevalence of Rubella Virus in Pregnant Women Attending at Maternity Lucrécia Paim, Luanda, Angola. The 2018 PharmSci 360, T1230-04-027. Ref: https://www.eventscribe. net/2018/PharmSci360/fsPopup.asp?efp=UUFSQIZZVFM10TQ2\&Pos terlD=165821\&rnd=0.8183299\&mode=posterinfo

49. UNICEF. Tire as suas dúvidas sobre vacinas. 2018. Ref: https://www. unicef.org/angola/duvidas-sobre-vacinas

50. Ministério da Saúde. (MINSA). Vacina da rubéola na rede de saúde. Jornal de Angola. 28 de Abril, 2017. Ref: http://jornaldeangola.sapo. ao/sociedade/saude_e_educacao/vacina_da_rubeola_na_rede_de_ saude 